Article

\title{
A Differential Redox Regulation of the Pathways Metabolizing Glyceraldehyde-3-Phosphate Tunes the Production of Reducing Power in the Cytosol of Plant Cells
}

\author{
Claudia V. Piattoni, Sergio A. Guerrero and Alberto A. Iglesias * \\ Instituto de Agrobiotecnología del Litoral (IAL, CONICET-UNL), FBCB, Paraje "El Pozo", CC 242, \\ Santa Fe S3000ZAA, Argentina; E-Mails: piattoni@fbcb.unl.edu.ar (C.V.P.); \\ sguerrer@fbcb.unl.edu.ar (S.A.G.) \\ * Author to whom correspondence should be addressed; E-Mail: iglesias@fbcb.unl.edu.ar; \\ Tel./Fax: +54-342-457-5209 (ext. 217).
}

Received: 10 January 2013; in revised form: 2 March 2013 / Accepted: 7 March 2013 /

Published: 12 April 2013

\begin{abstract}
Adaptation to aerobic life leads organisms to sense reactive oxygen species and use the signal for coordination of the entire metabolism. Glycolysis in plants is a particular network where specific steps, like oxidation of glyceraldehydes-3-phosphate (Ga3P), are critical in order for it to function. The triose-phosphate can be converted into 3-phosphoglycerate through the phosphorylating Ga3P dehydrogenase (Ga3PDHase, EC 1.2.1.12) producing ATP and NADH, or via the non-phosphorylating enzyme ( $n$-Ga3PDHase; EC 1.2.1.9) generating NADPH. In this work we found redox regulation to be a posttranslational mechanism allowing the fine-tuning of the triose-phosphate fate. Both enzymes were inactivated after oxidation by reactive oxygen and nitrogen species. Kinetic studies determined that Ga3PDHase is marked (63-fold) more sensitive to oxidants than $n p$-Ga3PDHase. Thioredoxin- $h$ reverted the oxidation of both enzymes (although with differences between them), suggesting a physiological redox regulation. The results support a metabolic scenario where the cytosolic triose-phosphate dehydrogenases are regulated under changeable redox conditions. This would allow coordinate production of NADPH or ATP through glycolysis, with oxidative signals triggering reducing power synthesis in the cytosol. The NADPH increment would favor antioxidant responses to cope with the oxidative situation, while the thioredoxin system would positively feedback NADPH production by maintaining $n p-G a 3 P D H a s e$ at its reduced active state.
\end{abstract}


Keywords: plant glycolysis; redox regulation; NADPH generation; ATP production; triose-phosphate dehydrogenase

\section{Introduction}

The glycolytic pathway is a catabolic process of high ubiquity between living cells and occupying a position of historical and philosophical importance in biochemistry. The characterization of glycolytic enzymes strongly contributed to evidence the occurrence of functional cell-free enzymatic processes [1]. Glycolysis, term first applied to describe the fermentation of glucose to lactic acid by muscle tissues, is now used in general to denote the pathway catabolizing sugars to pyruvic acid, which is later metabolized with many variants [1,2]. The so-called classical glycolysis is the cytosolic linear sequence of 10 enzymatic reactions that oxidizes hexoses to generate ATP, NADH, pyruvate, and building blocks for anabolism [2]. This type of glycolysis takes place in most kind of organisms, but in plants the pathway has some distinctive features. In photosynthetic organisms, the glycolytic route oddly occurs in parallel in two separated compartments, the cytosol and the plastids, which are interconnected by specific protein membrane transporters. On the other hand, glycolysis in the cytosol of plant cells is a particularly complex network with alternative enzymatic reactions at critical steps. The latter constitutes bypasses of the main pathway giving flexibility and unique regulatory aspects to the route [1,2]. In plants, glycolysis is the main fuel for respiration, since mitochondria in these organisms use glycolytically generated pyruvate and rarely fatty acids (but predominant in developing oilseeds) as main carbon and energy supplier. The glycolytic metabolism is also a key in plant heterotrophic tissues to deliver the carbon and energy source after the breakdown of starch or incoming sucrose, as these tissues cannot photosynthesize triose-P [2]. Despite many characteristics of the enzymes involved in branch points of the glycolytic route were determined, regulatory mechanisms related to their functioning under different cell situations are still poorly understood.

The present work is centered on the study of two plant cytosolic enzymes mediating alternative pathways for the oxidation of glyceraldehyde-3-phosphate (Ga3P), to 3-phosphoglycerate (3PGA) [1-3]. Through classic glycolysis, the process occurs by two consecutive enzymes [2,3]. First, the reversible $\mathrm{NAD}^{+}$-dependent Ga3P dehydrogenase (EC 1.2.1.12, Ga3PDHase) oxidizes Ga3P with coupled phosphorolysis to generate $\mathrm{NADH}$ and 1,3-bis-PGA (Reaction I). The latter intermediate, a high-content energy compound, allows phosphorylation at the substrate level (Reaction II) catalyzed by phosphoglycerate kinase (EC 2.7.2.3, PGKase). The alternative pathway is performed irreversibly in one step by oxidation tied to hydrolysis (rather than phosphorolysis) mediated by the non-phosphorylating $\mathrm{NADP}^{+}$-dependent Ga3PDHase (EC 1.2.1.9, $n p$-Ga3PDHase) to generate NADPH (Reaction III) (see [3] for details). The parallel occurrence of both routes sets out an important difference for cell energetic, since depending on the relative levels of activity of each triose-P DHase the oxidation of Ga3P will provide different amounts of energy (ATP) and/or reducing power (NADPH) in the cytosol $[2,3]$. 


$$
\begin{array}{ll}
\mathrm{Ga} 3 \mathrm{P}+\mathrm{NAD}^{+}+\mathrm{Pi} \leftrightarrow \text { 1,3-bis-PGA }+\mathrm{NADH}+\mathrm{H}^{+} & (\text {Reaction I) } \\
1,3-\mathrm{bis}-\mathrm{PGA}+\mathrm{ADP} \leftrightarrow 3 \mathrm{PGA}+\mathrm{ATP} & \text { (Reaction II) } \\
\mathrm{Ga} 3 \mathrm{P}+\mathrm{NADP}^{+}+\mathrm{H}_{2} \mathrm{O} \rightarrow 3 \mathrm{PGA}+\mathrm{NADPH}+2 \mathrm{H}^{+} & \text {(Reaction III) }
\end{array}
$$

The physiological function played by $n p$-Ga3PDHase in plants and the occurrence of mechanisms regulating its activity have been evidenced [4-8]. An Arabidopsis mutant lacking this enzyme was characterized as having altered morphology of siliques, inhibited glycolytic flux, decreased $\mathrm{CO}_{2}$ fixation capacity, and increased sensitivity to oxidative stress [8]. In agreement with the latter, the activity of $n p$-Ga3PDHase was found to increase up to 2-fold when wheat and maize seedlings were exposed to oxidative conditions imposed by methylviologen [4]. The effect observed under moderate oxidant concentrations was shown to be a consequence of a significant stability of the enzyme rather than to mRNA induction. On the other hand, $n p$-Ga3PDHase was identified as a target for posttranslational phosphorylation in non-photosynthetic plant tissues [5]. The phosphorylated enzyme exhibits distinctive kinetic properties after interaction with 14-3-3 regulatory proteins, becoming less active and more sensitive to regulation by adenylates and inorganic pyrophosphate [6]. Recently [7], we revealed that serine-404 in the wheat $n p$-Ga3PDHase is phosphorylated by a member of the SnRK1 (SNF1-related protein kinase) family, a system playing key roles for major integration of energy signaling and growth in plants [9].

Concerning plant Ga3PDHase, its functionality, regulation and involvement in stress situations have also been reported [10-13]. Arabidopsis lines deficient in this enzyme exhibit delayed growth, low number of seeds and siliques with altered morphology [13]. A proteomic approach analysis identified the enzyme as the most prominent protein modified by hydrogen peroxide $\left(\mathrm{H}_{2} \mathrm{O}_{2}\right)$ in the cytosol of Arabidopsis thaliana [11]. Also, in vitro studies showed inactivation of the enzyme after oxidation with $\mathrm{H}_{2} \mathrm{O}_{2}$, oxidized glutathione (GSSG), and $S$-nitrosogluthathione (GSNO); being the process reverted by dithiotreitol (DTT) and reduced glutathione (GSH) [11,12]. Recently [10], work performed with the recombinant enzyme from Arabidopsis revealed that oxidation of the protein involves formation of sulfenates that can drive the oxidation to an irreversible situation. Albeit, in the presence of GSH Ga3PDHase can reach glutathionylated (inactive) forms, which can be rescued by plant cytosolic glutaredoxin. Interestingly, it was determined that thioredoxin from plants are functional contributors to recover the enzyme from the mixed disulfide state.

Despite the previous findings, studies to comparatively understand the regulation of both cytosolic Ga3PDHases at the molecular level are lacking. In this work, we utilize the enzymes from wheat, produced recombinantly with high purity, to characterize their respective responses to redox modification. We determined that both enzymes are in vitro inactivated by oxidation with reactive oxygen and nitrogen species (ROS and RNS, respectively); and they were effectively recovered from the oxidative state by thioredoxin- $h(\mathrm{TRX}-h)$ from wheat. Ga3PDHase was markedly more sensitive to oxidation (also more inert to later reduction) than $n p$-Ga3PDHase. Results are analyzed in the metabolic scenario where cytosolic triose-P intermediates are rerouted toward increase synthesis of NADPH under oxidative cell conditions. 


\section{Results}

Both wheat triose-P DHases were produced as recombinant enzymes (via heterologous expression in Escherichia coli) highly purified (see Supplementary Figure S1) by immobilized metal ion affinity chromatography (IMAC), as was previously described for the $n p$-Ga3PDHase [14]. The Ga3PDHase was obtained as a homotetrameric protein (as determined by gel filtration on Superdex 200, Supplementary Figure S2) exhibiting $S_{0.5}$ values for $\operatorname{NAD}^{+}(136 \mu \mathrm{M})$ and Ga3P $(86 \mu \mathrm{M})$ similar to those reported for the enzyme purified from pea shoot and seed [15]; while $V_{\max }(38 \mathrm{U} / \mathrm{mg}$ ) was found in agreement with that reported for the recombinant Arabidopsis Ga3PDHase [12]. Also, the kinetic and structural properties of the $n p$-Ga3PDHase were coincident with the behavior of the enzyme purified from plants, as detailed before [14]. Thus, recombinant production renders both wheat enzymes as proteins that are kinetically and structurally comparable to those obtained from the natural source and consequently accurate for biochemical studies.

To analyze the effect of redox agents on $n p$-Ga3PDHase and Ga3PDHase we incubated each purified enzyme with the redox chemical agent diamide (oxidant) or DTT (reductant) and determined the activity at different times. Figure 1 shows that diamide inactivated both enzymes, although Ga3PDHase lost its activity more rapidly than $n p$-Ga3PDHase. Interestingly, following the addition of DTT both oxidized enzymes recovered the activity (Figure 1), data reinforcing a redox dependence of the proteins' catalytic capacity. Although neither diamide nor DTT are cellular components, our in vitro results suggest that posttranslational modifications by redox mechanisms could be involved in regulating the activity of these enzymes. To further explore about a physiological significance for such a regulation we evaluated the exposure of cytosolic triose-P DHases to redox agents found in plant cells; specifically: (i) the ROS compound $\mathrm{H}_{2} \mathrm{O}_{2}$, (ii) sodium nitroprusside (SNP) which is a donor of the RNS nitric oxide, (iii) glutathione (either GSSG or GSH), and (iv) wheat TRX- $h$.

Figure 1. The effect of chemical redox compounds on enzyme activity. (a) $n p$-Ga3PDHase; (b) Ga3PDHase. Each enzyme was incubated as detailed under Experimental Section. When indicated by the arrows it was added $1 \mathrm{mM}$ diamide and then $10 \mathrm{mM}$ dithiotreitol (DTT). At the specified time aliquots were withdrawn and assayed for the respective enzymatic activity. At the beginning of oxidation assays both enzymes were fully active (100\%): (a) $21 \mathrm{U} / \mathrm{mg}$ and (b) $38 \mathrm{U} / \mathrm{mg}$. Error bars represent the values deviation in three independent assays.

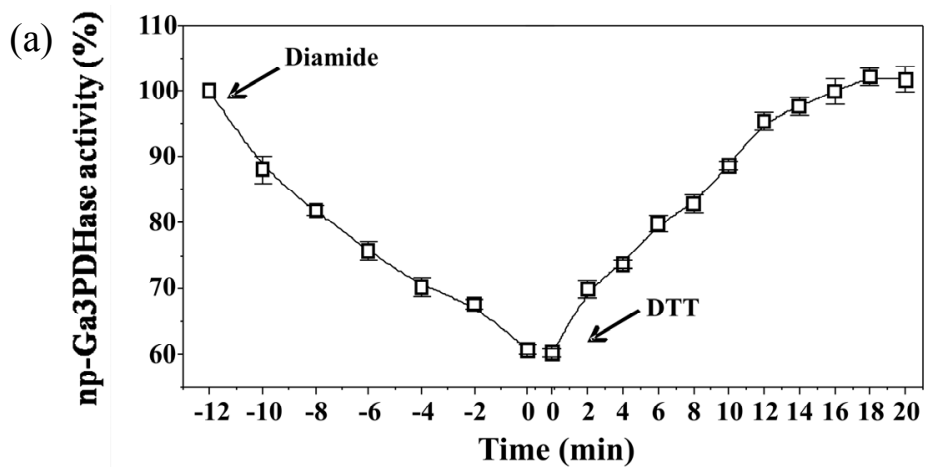


Figure 1. Cont.

(b)

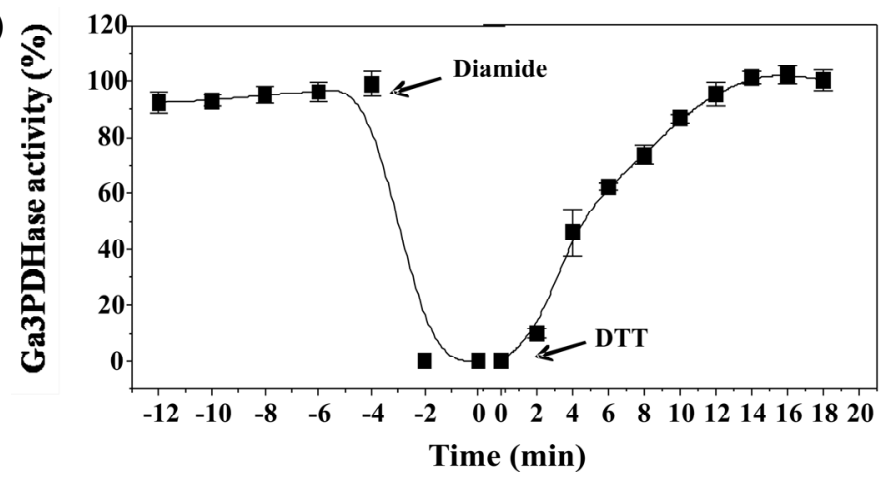

Figure 2. Enzyme inactivation caused by oxidation with $\mathrm{H}_{2} \mathrm{O}_{2}$, nitroprusside (SNP), and GSSG. Progressive inactivation of each triose-P DHase after treatment with the different physiological oxidants as detailed in the Experimental Section. (a) Incubation of $n p$-Ga3PDHase with: No further addition (०), $3 \mathrm{mM} \mathrm{H}_{2} \mathrm{O}_{2}(\square), 5 \mathrm{mM} \mathrm{SNP}(\diamond)$ or $20 \mathrm{mM}$ GSSG ( $\Delta$ ). (b) Incubation of Ga3PDHase with: No further addition (•), $1 \mathrm{mM} \mathrm{H}_{2} \mathrm{O}_{2}(\boldsymbol{\bullet})$, $1 \mathrm{mM}$ SNP $(\diamond)$ or $20 \mathrm{mM} \mathrm{GSSG}(\boldsymbol{\Delta})$. One hundred percent of activity corresponds to $21 \mathrm{U} / \mathrm{mg}$ and $38 \mathrm{U} / \mathrm{mg}$ in (a) and (b), respectively. Error bars represent the values deviation in three independent assays.

(a)

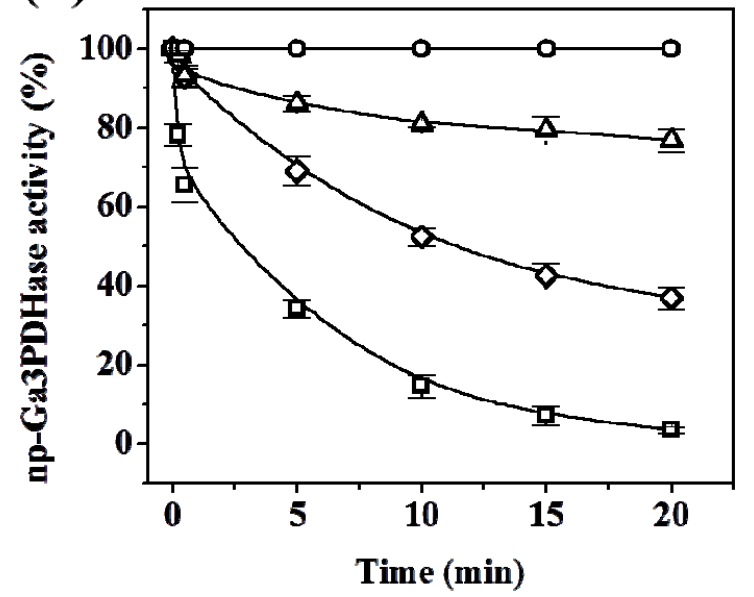

(b)

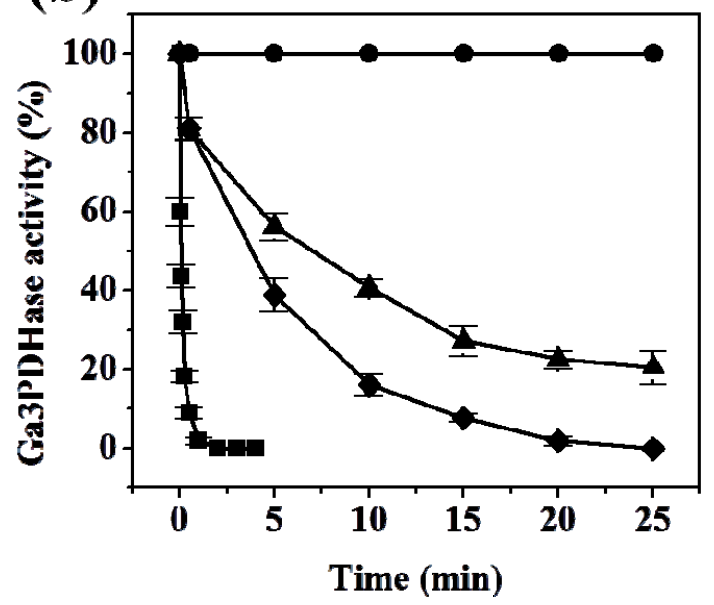

As shown in Figure 2, $n p$-Ga3PDHase and Ga3PDHase were inactivated to different degree after incubation with the physiological oxidants $\mathrm{H}_{2} \mathrm{O}_{2}$, SNP and GSSG. A first detailed observation indicates that the $\mathrm{NAD}^{+}$-dependent (EC 1.2.1.12) enzyme is more sensitive to the oxidants (remarkably toward $\mathrm{H}_{2} \mathrm{O}_{2}$ ) than the $n p$-Ga3PDHase. For a better characterization of the dissimilar sensitivity of the enzymes we performed a kinetic study of the loss of activity caused for each of the oxidants. Inactivation was dependent on time and the concentration of the respective compound, as the oxidative treatments coursed via chemical modification of thiol groups from critical cysteine residues in the respective enzyme. Using the model proposed by Kitz and Wilson [16] for the irreversible inhibition of enzymes (see Experimental Section), we determined the kinetic parameters detailed in Table 1, which evaluate the degree of effectiveness (directly related to the value of $k$ ") for each inhibitor as well as the mechanism by which they modify (inactivate) each triose-P DHase. As shown, for both enzymes the 
effectiveness of the oxidants followed the same order: $\mathrm{H}_{2} \mathrm{O}_{2}>$ SNP $>$ GSSG. From an analysis of Table 1 it is clear that for each oxidant the value of $k$ " determined for Ga3PDHase resulted significantly higher than that of the non-phosphorylating enzyme (EC 1.2.1.9), which indicates that the former DHase is more sensitive to oxidation by the respective redox agent. The most outstanding situation is oxidation by $\mathrm{H}_{2} \mathrm{O}_{2}$, where the $k$ " value for Ga3PDHase is 63 -fold higher than that obtained for $n p$-Ga3PDHase. Also, oxidation of the $\mathrm{NAD}^{+}$-dependent enzyme by $\mathrm{H}_{2} \mathrm{O}_{2}$ was 26 -fold and 700-fold higher than by SNP and GSSG, respectively; whereas $n p$-Ga3PDHase oxidation by $\mathrm{H}_{2} \mathrm{O}_{2}$ and SNP were in the same order. GSSG exhibited a very modest effect on the latter enzyme (Table 1). For both enzymes, inactivation caused by $\mathrm{H}_{2} \mathrm{O}_{2}$ coursed in one step, with practically no formation of one stable enzyme-inhibitor intermediate, while for the other two oxidants the mechanism occurred in two steps. Following the model developed by Kitz and Wilson [16] (see details under Experimental Section), oxidation by SNP and GSSG course with a first step where these compounds form a reversible intermediary complex with the enzyme, to follow a second step that leads to the formation of a covalent bond (the disulfide bridge) turning the reaction irreversible.

Table 1. Kinetic parameters for the oxidation of recombinant $n p$-Ga3PDHase and Ga3PDHase with $\mathrm{H}_{2} \mathrm{O}_{2}$, SNP or GSSG. Values were calculated using the irreversible inhibitor model as described under the Experimental Section. Oxidation of both enzymes by SNP and GSSG occurred in two-step (T; with formation of an intermediary complex EI) while $\mathrm{H}_{2} \mathrm{O}_{2}$ oxidation mechanism occurred in one-step $(\mathrm{O}$, with no appreciable formation of an intermediary complex).

\begin{tabular}{|c|c|c|c|c|}
\hline Oxidant & Mechanism & $k_{\mathrm{i}}\left(\min ^{-1}\right)$ & $K_{\mathrm{i}}(\mathrm{mM})$ & $k^{\prime \prime}\left(M^{-1} s^{-1}\right)$ \\
\hline \multicolumn{5}{|c|}{$n p$-Ga3PDHase } \\
\hline $\mathrm{H}_{2} \mathrm{O}_{2}$ & $\mathrm{O}$ & nd $*$ & nd & 1.9 \\
\hline SNP & $\mathrm{T}$ & 0.036 & 0.6 & 1.0 \\
\hline GSSG & $\mathrm{T}$ & 0.011 & 2.50 & 0.07 \\
\hline \multicolumn{5}{|c|}{ Ga3PDHase } \\
\hline $\mathrm{H}_{2} \mathrm{O}_{2}$ & $\mathrm{O}$ & nd & nd & 115.0 \\
\hline SNP & $\mathrm{T}$ & 1.3 & 4.8 & 4.5 \\
\hline GSSG & $\mathrm{T}$ & 0.13 & 12.30 & 0.17 \\
\hline
\end{tabular}

* nd: not determined.

It has been described [3,17-19] that, with same differences, the enzymatic mechanism of Ga3PDHase and $n p$-Ga3PDHase comprises the formation of a thiohemiacetal between Ga3P and an essential Cys residue (highly conserved in these enzymes, being Cys ${ }^{154}$ and $\mathrm{Cys}^{298}$ those corresponding to the respective wheat protein). The catalytic Cys residues need to be in the reduced state to carry out the catalytic process. To evaluate the possible involvement of these essential Cys residues in the oxidation treatment under study, we tested the effect of the substrates on the inactivation exerted by $\mathrm{H}_{2} \mathrm{O}_{2}$ for both enzymes (Figure 3). The presence of $\mathrm{NADP}^{+}$(but not that of Ga3P) protected $n p$-Ga3PDHase against inactivation by the oxidant (Figure 3a). The degree of protection was dependent on the dinucleotide concentration in the modification medium, after which we were able to calculate a $K_{\mathrm{d}}$ of $2.5 \mu \mathrm{M}$ for the binding of the substrate (see Experimental Section). In the case of Ga3PDHase, the presence of Ga3P or $\mathrm{NAD}^{+}$separately produce no important change in the 
modification, but the combined addition of both substrates effectively exerted a protective effect (Figure $3 \mathrm{~b}$ ). The degree of protection in this case was not highly affected by different concentrations of $\mathrm{NAD}^{+}$, but it was variable respect to Ga3P in a concentration dependent manner (with a $K_{\mathrm{d}}$ for the triose-P calculated in $115 \mu \mathrm{M}$ in the presence of $1 \mathrm{mM} \mathrm{NAD}^{+}$).

Figure 3. Inactivation of each triose-P DHase by $\mathrm{H}_{2} \mathrm{O}_{2}$ in the presence of substrates. (a) Incubation of $n p$-Ga3PDHase $\left(100 \%\right.$ activity of $21 \mathrm{U} / \mathrm{mg}$ ) with $1 \mathrm{mM} \mathrm{H}_{2} \mathrm{O}_{2}$ in the presence of none $(\Delta), 1 \mathrm{mM} \mathrm{Ga3P}(\square)$ or $100 \mu \mathrm{M} \mathrm{NADP}{ }^{+}(\diamond)$. Oxidation was followed in time during $20 \mathrm{~min}$ at $25{ }^{\circ} \mathrm{C}$; (b) Incubation of Ga3PDHase $(100 \%$ of activity of $38 \mathrm{U} / \mathrm{mg})$ with $0.5 \mathrm{mM} \mathrm{H}_{2} \mathrm{O}_{2}$ in the presence of none $(\boldsymbol{\Delta}), 1 \mathrm{mM} \mathrm{NAD}^{+}(\bullet), 1.2 \mathrm{mM} \mathrm{Ga} 3 \mathrm{P}(\boldsymbol{\nabla})$ or $1 \mathrm{mM}$ $\mathrm{NAD}^{+}$plus $1.2 \mathrm{mM} \mathrm{Ga3P}(\mathbf{})$. Oxidation was followed in time during $40 \mathrm{~s}$ at $25^{\circ} \mathrm{C}$. Error bars represent the values deviation in three independent assays.
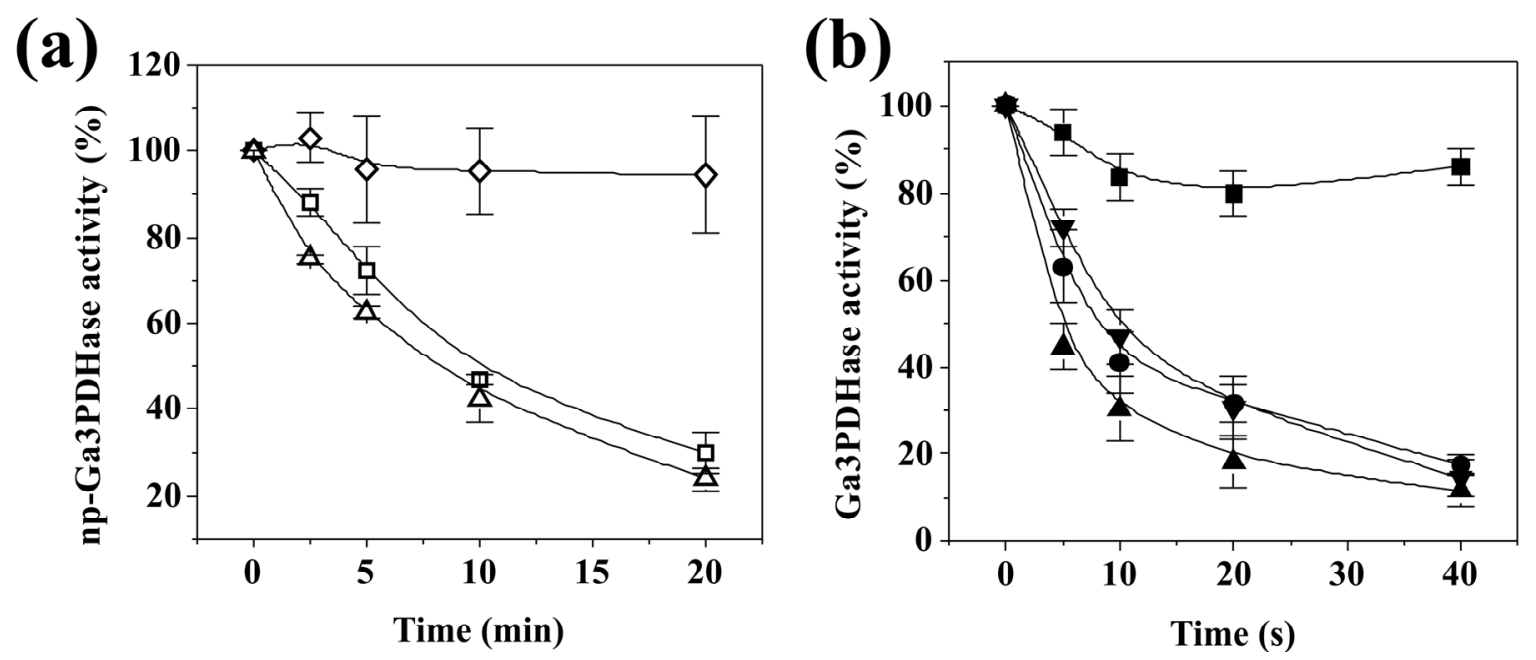

Results on the protection by substrates agree with the catalytic mechanism described for $n p$-Ga3PDHase, where NADP ${ }^{+}$binds first to the enzyme and induces a local structural re-arrangement making accessible and leaving well positioned the catalytic Cys residue to form a competent thiohemiacetal intermediate [18]. Although $\mathrm{NADP}^{+}$binding was found to expose the catalytic Cys residue, it seems that the conformational change could not favor the reaction of the enzyme with $\mathrm{H}_{2} \mathrm{O}_{2}$, giving no specific insight about the involvement of that Cys residue in the redox regulation mechanism. Concerning the protective effect of Ga3P combined with $\mathrm{NAD}^{+}$to the oxidation of Ga3PDHase, it is in concordance with the catalytic mechanism described for the enzyme from mammals and bacteria [17], where the triose-P forms the thiohemiacetal derivative in the presence of $\mathrm{NAD}^{+}$, and suggest that the essential Cys ${ }^{154}$ residue could be at least one of the residues being modified by oxidation. On the other hand, the $K_{\mathrm{d}}$ values determined for the respective substrate giving protection to inactivation are similar to the corresponding $S_{0.5}$ obtained kinetically (detailed above) for each triose-P DHase.

It is widely known that posttranslational regulation by redox mechanisms comprises the activation or inactivation of enzyme activity by the occurrence of reversible oxidation-reduction reactions $[9,20,21]$. In order to test if the oxidation of Ga3PDHase and/or $n p-\mathrm{Ga} 3$ PDHase by $\mathrm{H}_{2} \mathrm{O}_{2}$ is possible to be reverted by reducing physiological components, we incubated the oxidized enzymes 
with variable concentrations of recombinant reduced TRX- $h$ and followed the reaction by enzyme activity assays.

Activity of both proteins was completely restored by reductive treatment with increasing concentrations $(\mu \mathrm{M})$ of reduced TRX- $h$ (Figure 4). These results suggest that regulation of both cytosolic triose-P DHases by reversible redox mechanisms could occur in vivo under specific circumstances. To further analyze the reduction process, we evaluated the reduction of both enzymes by TRX- $h$ after increasing oxidation times (Figure 5). Figure 5a shows that the recovery of activity of $n p$-Ga3PDHase by TRX- $h$ took place independently of the inactivation degree reached by oxidation. According to Figure $5 \mathrm{~b}$ the reversion by TRX- $h$ is different for Ga3PDHase, as it was effectively exerted on the enzyme inactivated up to a certain level, beyond which the reduction becomes inefficient. It is worth mentioning that, for the Ga3PDHase, similar results were obtained when GSH was the reductant, although the latter was not able to reactivate the $n p$-Ga3PDHase (data not shown). In our hands, the effect of TRX- $h$ was only in one direction, as its oxidized form had no inhibitory effect on the activity of any of the triose-P DHases under study.

Figure 4. Effect of thioredoxin- $h(\mathrm{TRX}-h)$ on inactive triose-P DHases. $n p-G a 3 P D H a s e$ (open symbols) was oxidized with $1 \mathrm{mM} \mathrm{H}_{2} \mathrm{O}_{2}$ during $30 \mathrm{~min}$, desalted and then incubated with the stated concentrations of reduce TRX- $h$ during $30 \mathrm{~min}$. Ga3PDHase (filled symbols) was oxidized with $0.5 \mathrm{mM} \mathrm{H} \mathrm{H}_{2} \mathrm{O}_{2}$ during $30 \mathrm{~s}$ and the oxidation stopped by addition of catalase $(10 \mathrm{U})$. The enzyme was highly diluted and incubated in the presence of the stated concentrations of TRX- $h$ during $2 \mathrm{~min}$. One hundred percent of activity corresponds to $21 \mathrm{U} / \mathrm{mg}$ and $38 \mathrm{U} / \mathrm{mg}$ for $n p$-Ga3PDHase and Ga3PDHase, respectively.

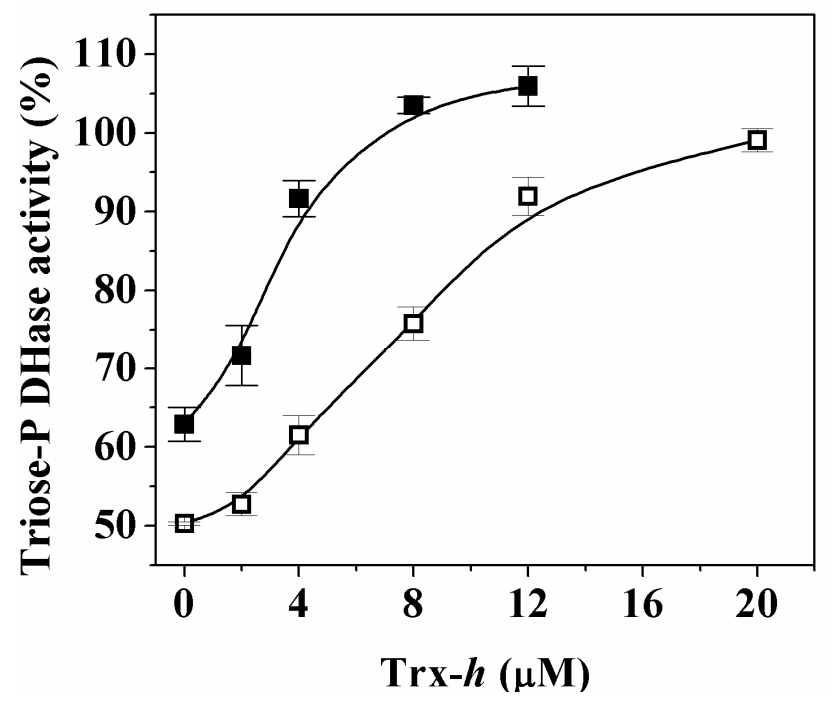

Results showed herein indicate that redox regulation of each triose-P DHase would occur by different mechanisms. Results tempt us to speculate that $n p$-Ga3PDHase oxidation would occur by forming of a disulfide bond, which can be reverted by TRX- $h$, as it was previously reported [22]. Using DTNB (see Experimental Section) we quantified $1.8 \pm 0.3$ and $6.2 \pm 0.4$ accessible cysteinyl moieties for the oxidized and reduced enzyme, respectively. This assent with the oxidation of four Cys residues that would course by the formation of at least one disulfide bridge (modification being responsible for enzyme inactivation). On the other hand, oxidation of Ga3PDHase seems to occur by a 
more complex mechanism. The formation of a disulfide bridge during oxidation of this enzyme cannot be discarded, as TRX- $h$ can conspicuously restore enzyme activity. In fact, $1.0 \pm 0.2$ Cys was titrated in the oxidized enzyme and $3.1 \pm 0.4$ after reduction, which shows that two Cys lost the thiol form after oxidation, independently of the mechanism of oxidation. However, reversibility in the redox process for Ga3PDHase takes place only partially or depending on the degree of previous exposure to oxidants. When the oxidative treatment reaches a certain condition, it looks like if oxidation of Ga3PDHase thiol groups leads to the formation of sulfenic, sulfinic and sulfonic acids, as previously described for the enzyme from Arabidopsis [10]. Thus, reduction of Ga3PDHase by TRX- $h$ (or GSH for this enzyme) would be possible if the disulfide bond is formed (perhaps also if oxidation renders sulfenic acid), but oxidation to higher extents would turn the process irreversible.

Figure 5. Treatment with TRX- $h$ of triose-P DHases inactivated to different degrees. (a) $n p$-Ga3PDHase was oxidized with $1 \mathrm{mM} \mathrm{H} \mathrm{H}_{2} \mathrm{O}_{2}$ during 0 to 60 min to reach different activity values (shown in \% by front bars, Ox). Samples were desalted and then incubated with $20 \mu \mathrm{M}$ TRX- $h$ during $30 \mathrm{~min}$, after which activity was assayed for activity (shown by rear bars, gray); (b) Ga3PDHase was oxidized with $0.5 \mathrm{mM} \mathrm{H}_{2} \mathrm{O}_{2}$ during 0 to 5 min to reach different activity values (shown in \% by front bars, Ox). After stopping the oxidation by adding catalase $(10 \mathrm{U})$, the respective samples were desalted, incubated with $12 \mu \mathrm{M}$ TRX- $h$ during $30 \mathrm{~min}$ and then assayed for activity (shown by rear bars, gray). One hundred percent of activity corresponds to $21 \mathrm{U} / \mathrm{mg}$ and $38 \mathrm{U} / \mathrm{mg}$ in (a) and (b), respectively. All assays were repeated at least three times and were reproducible within $\pm 10 \%$.

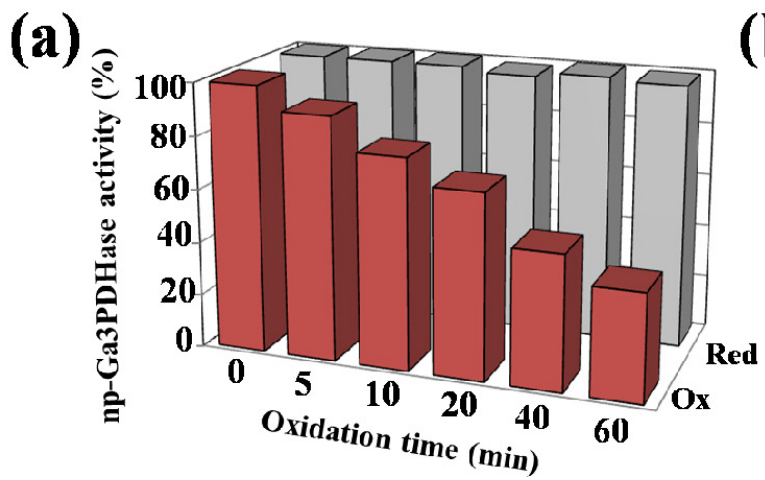

(b)

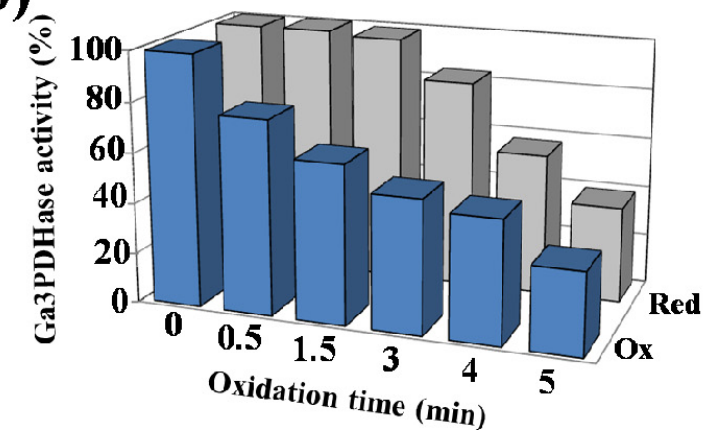

It has been reported that oxidative stress induces oligomerization and aggregation of human Ga3PDHase [23]. To check if over-oxidation provokes a similar effect on the plant recombinant triose-P DHases, we tested the oxidation of each enzyme by $\mathrm{H}_{2} \mathrm{O}_{2}$ at $37{ }^{\circ} \mathrm{C}$ and measured the turbidity during the $24 \mathrm{~h}$ treatment. Changes in the enzymes solubility (treated in vitro with or without $\mathrm{H}_{2} \mathrm{O}_{2}$ ) are represented in Figure 6. As shown, the absorbance for solutions of both enzymes remained with no significant change during a first period $(\sim 1 \mathrm{~h})$ of exposure to the oxidant. However, the analysis of results in Figure 6 clearly indicates that after the first hour, further treatment of Ga3PDHase with $\mathrm{H}_{2} \mathrm{O}_{2}$ (but not that of $n p$-Ga3PDhase) caused an increase in the turbidity. The precipitation of Ga3PDHase treated with $\mathrm{H}_{2} \mathrm{O}_{2}$ was also appreciated in an SDS-PAGE electrophoresis, in which resolution of the soluble and insoluble protein fractions (previously separated by centrifugation), showed a time dependent increase of the latter, with a concomitant decrease in the soluble protein (not shown). 
Figure 6. Over-oxidation of the triose- $\mathrm{P}$ DHases with $\mathrm{H}_{2} \mathrm{O}_{2}$. Time course turbidity followed by changes at $405 \mathrm{~nm}$ for solutions $(0.6 \mathrm{mg} / \mathrm{mL})$ of $n p$-Ga3PDHase (open symbols) or Ga3PDHase (filled symbols) treated with none (circles) or with $1 \mathrm{mM} \mathrm{H}_{2} \mathrm{O}_{2}$ (squares). Error bars show deviation of determinations assayed as independent triplicates.

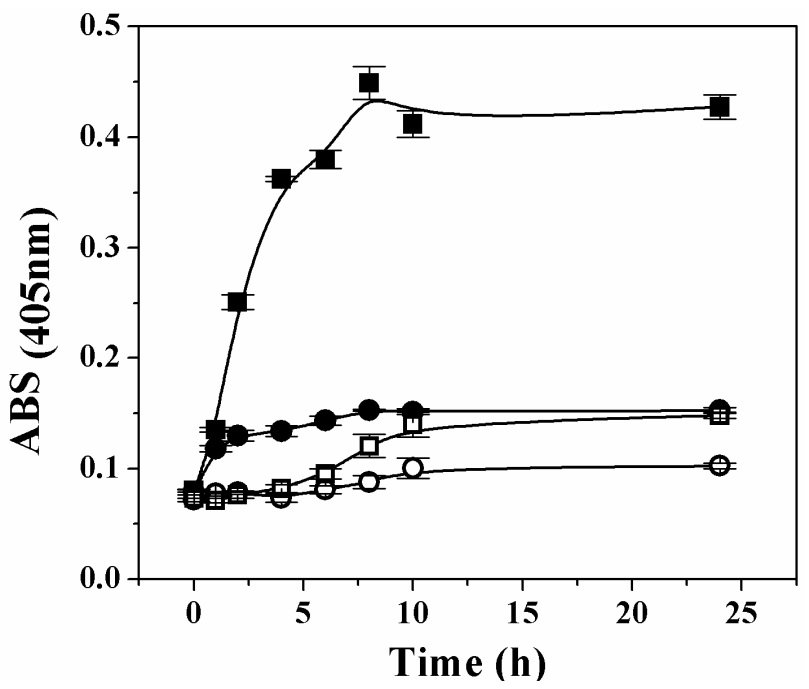

\section{Discussion}

Herein we show that posttranslational redox modifications affect the activity of both cytosolic triose-P DHases, but in different ways. For both enzymes, the activity was slowed down by oxidizing agents related to ROS $\left(\mathrm{H}_{2} \mathrm{O}_{2}\right)$, RNS (generated by SNP light exposure) and other physiological components (GSSG), but the reactivity of each DHase was different. Kinetic characterization of the oxidation reactions indicates that Ga3PDHase is more sensitive to oxidation (especially by $\mathrm{H}_{2} \mathrm{O}_{2}$ ) than $n p$-Ga3PDHase, as the $k$ " values obtained for the former were significantly higher (Table 1). Moreover, the addition of substrates attenuated inactivation by oxidation (Figure 3), in a way that agrees with the catalytic mechanism already described for each enzyme. As it was described, both enzymes have a cysteine residue (Cys ${ }^{154}$ in Ga3PDHase and $\mathrm{Cys}^{298}$ in np-Ga3PDHase from wheat) involved in the catalytic process which needs to be in the reduced state to form a thiohemiacetal intermediate with Ga3P [19]. In the case of Ga3PDHase, the protective effect exerted by Ga3P (when $\mathrm{NAD}^{+}$is also present) suggests that $\mathrm{Cys}^{154}$ could be at least one of the residues being affected by oxidation. This fact was previously observed in the human (Cys ${ }^{149}$ in this case) [23] and the Arabidopsis ortholog enzymes [10].

Concerning $n p$-Ga3PDHase, the fact that its oxidation was protected by addition of NADP ${ }^{+}$ (Figure 3a), also agrees with the mechanism proposed for the enzymatic reaction (where $\mathrm{NADP}^{+}$is the first substrate interacting with the enzyme). However, the protective effect is not conclusive respect to if the catalytic $\mathrm{Cys}^{298}$ is actually affected by oxidation. In a previous report dealing with homology modeling of plant $n p$-Ga3PDHases [22] it was shown that two cysteine residues $\left(\mathrm{Cys}^{271}\right.$ and $\mathrm{Cys}^{422}$ in wheat $n p$-Ga3PDHase), strictly conserved in the sequence of plant enzymes and absent in the protein from prokaryotes, could form a disulfide bond. From the results showed herein (Figures 1, 2 and 7) and the previous structural study, it could be thought the occurrence of a disulfide bond between Cys ${ }^{271}$ and $\mathrm{Cys}^{422}$ as a mechanism that protects the catalytic $\mathrm{Cys}^{298}$ from oxidation with the consequence of 
obstructing the substrates binding. It would also be proposed that after $\mathrm{NADP}^{+}$binds to the enzyme, the proximity of that two Cys is modified as the structural change occurs, leaving them not correctly positioned to form the disulfide bridge. Altogether, the latter would allow a fine-tune regulation of $n p$-Ga3PDHase activity under different cellular conditions, which in turn will modify Ga3P partitioning and levels of NADPH synthesis.

Interestingly, we also found that the lost of activity of the two cytosolic triose-P DHases caused by oxidation with $\mathrm{H}_{2} \mathrm{O}_{2}$ could be efficiently reverted by reduction with micromolar concentrations of TRX- $h$, a cytosolic isoform of this family of proteins that play a key role in cellular redox regulation (Figure 4) [24,25]. While the TRX- $h$ dependent reduction of the $n p$-Ga3PDHase was possible independently of how long is the previous exposure to the oxidant; reduction of Ga3PDHase by TRX- $h$ was less effective when the exposure to oxidant increased the degree of inactivation of the enzyme (Figure 5). Our data support that redox regulation of Ga3PDHase and $n p$-Ga3PDHase could occur physiologically. Results indicate that oxidation of each triose-P DHase takes place by different mechanisms, as proposed by the speculative scheme shown in Figure 7.

In agreement with previous reports for human Ga3PDHase [23], we observed that $\mathrm{H}_{2} \mathrm{O}_{2}$ over-oxidation of wheat recombinant Ga3PDHase induced protein aggregation and precipitation, an effect not observed in wheat recombinant $n p$-Ga3PDHase (Figure 6). The latter particular property of the $\mathrm{NAD}^{+}$-dependent DHase (EC 1.2.1.12) would be functional in plant cells, probably associated with apoptosis after oxidative stress, a role found for the enzyme in human neurons [26,27]. Although irreversible protein oxidation triggers loss of native structure and functional activity, recent reports demonstrated that induced structural changes confer, to certain polypeptides, capacities to act as oxidative stress sensors. In this way, oxidized proteins become involved in several signal transduction routes (e.g., apoptosis activation), or they display "non-conventional" enzymatic activities (now acting as chaperones or transcriptional factors). In plants, as well as in mammals and some bacteria, an example of the latter is the 2Cys typical peroxiredoxin (2CysPRX) [28]. 2CysPRXs are peroxidases lacking prosthetic groups that mediate in the defense against oxidative stress by reducing $\mathrm{H}_{2} \mathrm{O}_{2}$ and alkyl hydroperoxides [29]. In addition to detoxifying peroxides, 2CysPRXs may be considered as peroxide sensors transmitting the presence of peroxides to upstream redox proteins; furthermore, the activities and properties of some Prx are regulated by overoxidation and nitrosylation [28]. As a whole, current information reported in plants agrees with that from animals, where it was demonstrated that Ga3PDHase is a multifunctional protein, with many roles besides its enzymatic activity in glycolysis [30]. Effectively, the enzyme from animals participates in nuclear events including gene transcription, RNA transport, DNA replication, and initiation of apoptotic cell death upon nitrosylation [26,27,30-33].

As a ROS, $\mathrm{H}_{2} \mathrm{O}_{2}$ has been given much attention during the past decades. A large amount of evidence has proven that $\mathrm{H}_{2} \mathrm{O}_{2}$ plays important roles as a signaling molecule in plants under unfriendly environmental conditions which include various biotic and abiotic stresses [20,34]. Also to some extent, an excess in $\mathrm{H}_{2} \mathrm{O}_{2}$ accumulation was shown that can lead to oxidative stress in plants, which then triggers cell death [35]. By its part, Ga3PDHase has emerged some years ago as a multifunctional enzyme involved in numerous cellular functions, and further investigations have yielded significant insight into its involvement in cellular response to oxidative stress and apoptosis in animal cells [30]. Regardless, much less is known about the non-enzymatic Ga3PDHase related functions in plants. After 
proteomic studies, it was proposed that Ga3PDHase could be involved in $\mathrm{H}_{2} \mathrm{O}_{2}$ perception $[11,36]$. Recently [37], it was also reported that cytosolic Ga3PDHase interact with the plasma membrane associated phospholipase D to translate the $\mathrm{ROS} \mathrm{H}_{2} \mathrm{O}_{2}$ signal in Arabidopsis, in a way mediating the plant response to absicic acid and water deficits. Nevertheless, many studies need to be done to elucidate specific non-enzymatic roles played by the protein in plant cells.

Figure 7. Scheme proposed for $n p$-Ga3PDHase and Ga3PDHase oxidation. Redox regulation of Ga3PDHase (EC 1.2.1.12) could probably take place by routes involving one or more cystein residues. When two thiol groups are involved, a disulfide bridge would occur; but, as results partially support, some Cys would escape disulfide formation and become irreversibly oxidized by formation of sulfenic $(\mathrm{SOH})$, sulfinic $\left(\mathrm{SO}_{2} \mathrm{H}\right)$ and sulfonic $\left(\mathrm{SO}_{3} \mathrm{H}\right)$ acid, depending on the oxidant involved, its concentration and the extent of the oxidation. Reduction of Ga3PDHase by TRX- $h$ could be possible from the disulfide bridge (eventually also from sulfenic acid, dashed arrows), but the oxidation to sulfinic and sulfonic acids turns irreversible and could promote protein aggregation and precipitation. By the other hand, redox regulation of $n p$-Ga3PDHase (EC 1.1.1.9) would occur by disulfide bond formation probably between two Cys residues different from the catalytic one (marked in blue), which can be reverted anytime by reduced TRX- $h$. The synthesis of NADPH by $n p$-Ga3PDHase under the incidence of an oxidative situation, would favor the activity of antioxidant systems (like thioredoxin (TRX) which involves the thioredoxin reductase (TRXR) that maintains TRX- $h$ in its reduced state). This would feedback NADPH production by maintaining the $n p-G a 3 P D H a s e$ in its reduced (active) state.

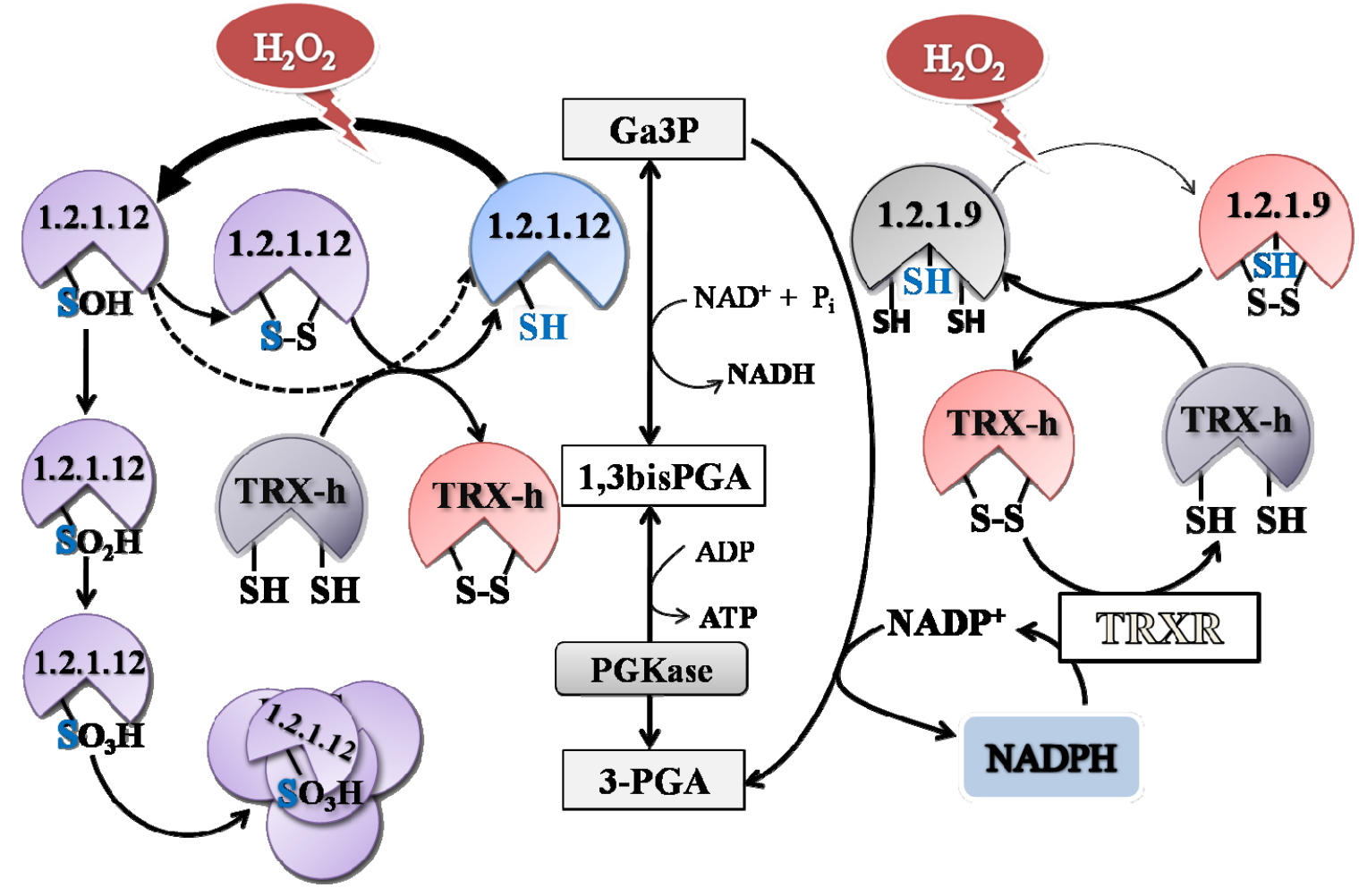


Recently, Taniguchi and Miyake [38] revisited the plant redox-shuttling systems between chloroplast and cytosol. In their review, the authors remark the importance of fine control of the malate/oxaloacetate and triose-P/3PGA shuttle systems to maintain adequate levels of reductant and proper metabolic balance. The triose-P DHases under study are the cytosolic components of the enzymes involved in the triose-P/3PGA shuttle system, while the triose-P translocator (located in the inner envelope membrane) together with the Ga3PDHase (EC 1.2.1.13) and PGKase of the Calvin-Benson cycle are the chloroplast counterparts. Our results give new insights at the molecular level on the regulatory mechanism acting on this shuttle system. The regulation agrees with the function of $n p$-Ga3PDHase as a cytosolic NADPH producing enzyme and its probable important role under oxidative conditions. In this sense, it has been reported that, in wheat and maize seedlings, the $n p$-Ga3PDHase activity increase up to 2-fold after oxidative stress conditions imposed by methylviologen, as a consequence of a significant stability of the active enzyme (not due to mRNA induction) [4].

Figure 8. Partitioning of Ga3P during cytosolic glycolysis under the presence of $\mathrm{H}_{2} \mathrm{O}_{2}$. The picture represents that the presence of $\mathrm{H}_{2} \mathrm{O}_{2}$ triggers an alert signal, inducing oxidation of both triose-P DHases. The higher sensitivity to the oxidant of the Ga3PDHase enzyme (EC 1.2.1.12) provokes high oxidation states of critical Cys residues, resulting in a reduction of this pathway for the Ga3P oxidation (marked lighter). Conversely, the $n p$-Ga3PDHase (EC 1.2.1.9) lower reactivity toward the oxidant makes the enzyme more stable, remaining active (considering also the reversion by TRX- $h$ ) and leading Ga3P to produce NADPH.

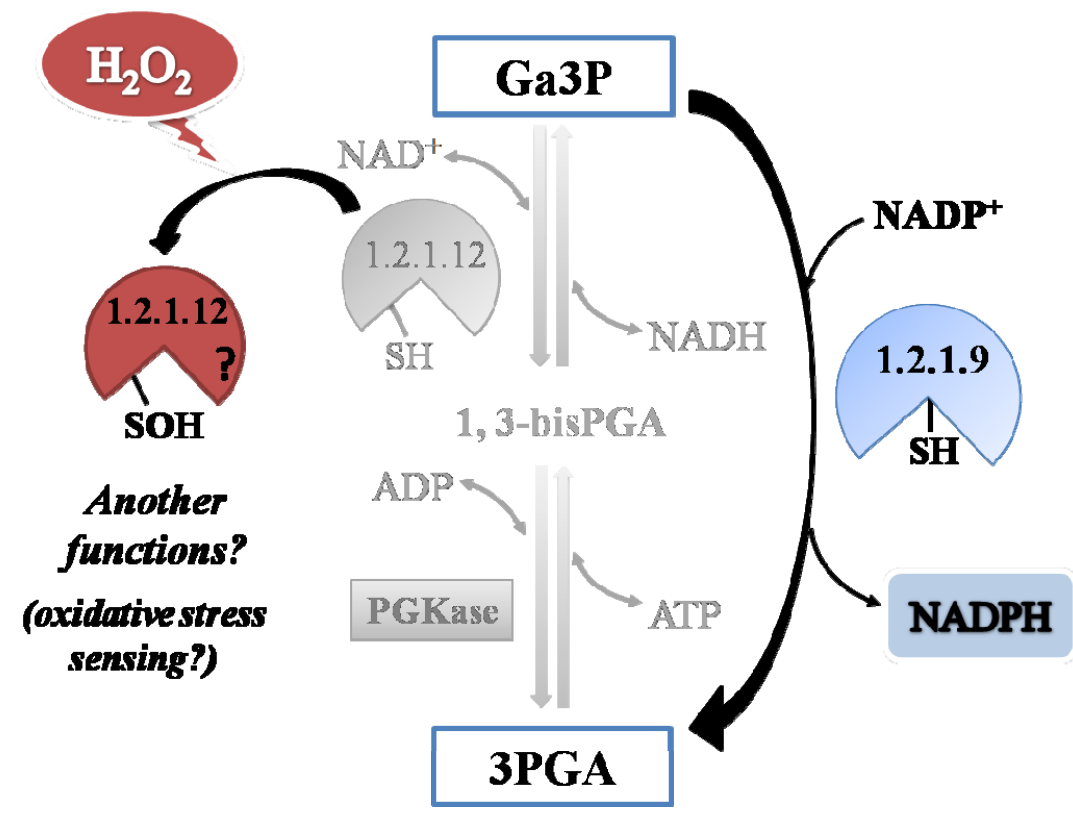

A comparative analysis of the kinetic constant values obtained for oxidation reactions of both Triose-P DHases let us to propose a redox scenario for Ga3P partitioning between these two pathways in the cytosol of plant cells (Figure 8). By this way, the presence of $\mathrm{H}_{2} \mathrm{O}_{2}$ would increase the metabolic flux of Ga3P through $n p$-Ga3PDHase, with the consequence increment in the synthesis of NADPH (given that $n p$-Ga3PDHase is significantly less reactive with $\mathrm{H}_{2} \mathrm{O}_{2}$ than Ga3PDHase). Enhanced NADPH synthesis would be beneficial for antioxidant systems coping with oxidative stress that 
depend on the reducing power to ameliorate the redox imbalance [21]. Furthermore, the process would feedback NADPH production maintaining $n p$-Ga3PDHase in reduced state by TRX- $h$ (which itself requires NADPH to be reduced by thioredoxin reductase). Therefore, the high reactivity of Ga3PDHase toward $\mathrm{H}_{2} \mathrm{O}_{2}$, would be related to its probable role as an oxidative sensor molecule.

Even when many studies on redox-regulated proteins and proteomic analyses have been reported [21,38], the knowledge of oxidative signal transduction pathways occurring in plants is far from complete. So far, our results are clearly in concordance with the physiological evidence already accounted on redox plant metabolism, and they allow assign a more detailed functioning of both triose-P DHases found in the cytosol of plant cells. Results obtained in this work, together with those published before, support the idea that $n p$-Ga3PDHase could be involved in the response to oxidative stress to assure the synthesis of NADPH, while Ga3PDHase could be a sensor of the occurrence of the oxidative stress and, after oxidation, acts as a signaling molecule.

\section{Experimental Section}

\subsection{Chemicals}

Rabbit muscle aldolase, $\mathrm{NAD}^{+}, \mathrm{NADP}^{+}$, NADH, NADPH, Fru1,6bisP, 3PGA, diamide, $\mathrm{H}_{2} \mathrm{O}_{2}$, sodium nitroprusside (SNP), and DTT were purchased from Sigma-Aldrich (St. Louis, MO, USA). All other reagents were of the highest quality available.

\subsection{Molecular Cloning, Expression and Purification of Recombinant Proteins}

Recombinant wheat $n p$-Ga3PDHase (NCBI accession $\mathrm{N}^{\circ}$ DQ268762) was obtained from Escherichia coli BL21-CodonPlus ${ }^{\circledR}$ (DE3)-RIL (Novagen, Madison, WI, USA) cells transformed with (pRSETB/TagapN) as previously described [14]. The genes coding for wheat Ga3PDHase (gapC, NCBI accesion $\mathrm{N}^{\circ}$ EF592180) and wheat TRX- $h$ (trxH, NCBI $\mathrm{N}^{\circ}$ AJ404845) were amplified from wheat (Triticum aestivum, Tae) leaves mRNA as it was previously described for $n p$-Ga3PDHase [14] with the following specific oligonucleotides: TaegapC fow (5'-GGATCCGATGGGCAAGATTAAGATCGG-3'), TaegapC rev (5'-GAATTCTTACTTGGTGCTGTGCATGTG-3'), TaetrxH fow (5'-GGATCCGAT GGCGGCGTCGGCGGCGAC-3') and TaetrxH rev (5'-AAGCTTTTACTGGGCCGCGTGTAGCC-3').

For protein expression purposes the amplified genes were subcloned in the pRSETB expression vector (Invitrogen, Carlsbad, CA, USA), being the constructions (pRSETB/TagapC) and (pRSETB/TatrxH) used to transform competent E. coli BL21 CodonPlus ${ }^{\circledR}(\mathrm{DE} 3)-\mathrm{RIL}$ cells. All proteins were expressed in LB medium and highly purified by ion metal affinity chromatography (IMAC) (Hi-Trap ${ }^{\text {TM }}$ Chelating HP, GE-Healthcare) as previously described for $n p$-Ga3PDHase [14]. Purified proteins were stored in elution buffer supplemented with $10 \mathrm{mM}$ 2-mercaptoethanol and 10\% $(v / v)$ glycerol at $-80{ }^{\circ} \mathrm{C}$ until use, conditions under which they were stable during at least 6 months.

\subsection{Protein Methods}

Total protein concentration was determined by the Bradford assay [39], using bovine serum albumin as standard. Protein electrophoresis under denatured conditions (SDS-PAGE) was performed as previously described by Laemmli [40]. 


\subsection{Ga3PDHase and np-Ga3PDHase Activity Assay and Kinetics Studies}

Ga3PDHase activity assay was performed following a protocol previously described with some modifications [13]. The reaction mixture $(50 \mu \mathrm{L})$ contained (unless otherwise specified): $50 \mathrm{mM}$ Tricine- $\mathrm{NaOH} \mathrm{pH} 8.5,1 \mathrm{mM} \mathrm{NAD}{ }^{+}, 10 \mathrm{mM}$ sodium arsenate, 0.4 units aldolase (rabbit muscle), $1.2 \mathrm{mM}$ fructose-1,6-bisphosphate (Fru1,6bisP), and an adequate quantity of enzyme.

The activity of $n p$-Ga3PDHase was assayed as previously described [41]. The reaction mixture $(50 \mu \mathrm{L})$ contained (unless otherwise specified): $50 \mathrm{mM}$ Tricine- $\mathrm{NaOH} \mathrm{pH} \mathrm{8.5,0.2} \mathrm{mM} \mathrm{NADP}$, 0.4 units aldolase (rabbit muscle), $1.2 \mathrm{mM}$ Fru1,6bisP, and an adequate quantity of enzyme.

In both cases the reaction was performed at $30 \mu \mathrm{C}$ and started with the addition of Fru1,6bisP. $\mathrm{NADH}$ or NADPH generation was monitored spectrophotometrically at $340 \mathrm{~nm}$. One unit (U) is defined as the amount of enzyme that catalyzes the formation of $1 \mu \mathrm{mol} \mathrm{NAD}(\mathrm{P}) \mathrm{H}$ per minute under the specified assay conditions.

For enzyme kinetics, saturation curves were performed by assaying the respective enzyme activity at saturating level of the fixed substrate and different concentrations of the variable substrate. Values of $S_{0.5}, V_{\max }$ and Hill numbers $\left(n_{\mathrm{H}}\right)$ were obtained fitting the experimental data to the generalized Hill equation using the Levenberg-Marquardt nonlinear least-squares algorithm provided by the computer program Origin $^{\mathrm{TM}}$ 7.0 All kinetic parameters are the mean of at least three determinations and were reproducible within at least $\pm 10 \%$.

\subsection{Oxidation Assay}

Purified Ga3PDHase and $n p$-Ga3PDHase were desalted using Microcon spin columns (Millipore) in $100 \mathrm{mM}$ Tris-HCl $\mathrm{pH} 8.0,0.1 \mathrm{mM}$ EDTA as a previous procedure to remove 2-mercaptoethanol (similar results were obtained at $\mathrm{pH}$ values between 7 and 8). For oxidation, $0.024 \mu \mathrm{g} / \mu \mathrm{L}$ of protein were incubated in the presence of different concentrations of either diamide, $\mathrm{H}_{2} \mathrm{O}_{2}$, SNP or GSSG, in buffer $100 \mathrm{mM}$ Tris-HCl pH 8.0, $0.1 \mathrm{mM}$ EDTA at $25^{\circ} \mathrm{C}$. The incubation with SNP was carried out with direct environment light to induce photolytic decomposition of the reagent and generate nitric oxide and other reactive nitrogen species. After different incubation times, aliquots were withdrawn, conveniently diluted and assayed for enzyme activity as above described.

\subsection{Kinetic Analysis of Oxidation Reactions}

The oxidation rate for Ga3PDHase and $n p$-Ga3PDHase, was followed by withdrawing samples for assay of activity at different time intervals after the mixing of the respective enzyme with at least six different concentrations of each oxidant. Experimental data were plotted as log remaining activity against the oxidation reaction time ( $\mathrm{min}$ or $\mathrm{s}$ ). Percentage of remaining activity was calculated taken as $100 \%$ the activity of the specific enzyme incubated under the same conditions but in the absence of oxidants. The first order rate constant $\left(k_{\text {app }}\right)$ for each oxidant concentration was calculated by fitting the curves to the equation: $\log$ relative activity $=2-k_{\text {app }} *$ t, with the software Origin ${ }^{\mathrm{TM}}$ 7.0. Plots of $k_{\text {app }}$ values $v s$. variable oxidant concentrations allowed identifying if the mechanism of inactivation coursed via one-step (the plot was linear) or two-step (the plot showed hyperbolic) model, as proposed by Kitz and Wilson [16] for the irreversible inhibition of enzymes: 


$$
E+I \stackrel{K_{\mathrm{i}}}{\rightleftarrows} E I \stackrel{k_{\mathrm{i}}}{\longrightarrow} E-I \quad k_{\text {app }}=k_{\mathrm{i}}^{*} I /\left(K_{\mathrm{i}}+I\right) \quad k^{\prime \prime}=k_{\mathrm{i}} / K_{\mathrm{i}}
$$

For this mechanism, $k_{\mathrm{i}}$ defines the maximum rate of inactivation that is achieved at an infinite concentration of inactivator, $K_{\mathrm{i}}$ describes the concentration of inhibitor yielding a rate of inactivation equal to half $k_{\mathrm{i}}$, and $k^{\prime \prime}=k_{\mathrm{i}} / K_{\mathrm{i}}$ is the second-order rate, which is considered to be the best measure of relative inactivator potency. When inactivation courses in one step $k_{\text {app }}=k " *(I)$ and the value of $k$ " is calculated directly by linear regression.

To calculate the dissociation constant $\left(K_{\mathrm{d}}\right)$ for the binding of the substrate to the respective triose-P PDHase, inactivation of the enzyme at a fixed concentration of $\mathrm{H}_{2} \mathrm{O}_{2}$ was afforded by different concentrations of Ga3P (in the presence on $\mathrm{NAD}^{+} 1 \mathrm{mM}$ ) for the Ga3PDHase, or different concentrations of $\mathrm{NADP}^{+}$in the case of the $n p$-Ga3PDHase. Inactivation kinetic data obtained in the different conditions were plotted according to Mildvan and Leigh [42], using the equation:

$$
1 / k_{\text {app }}^{\prime}=1 / k^{\prime}+a / K_{\mathrm{d}} * k^{\prime}
$$

where $k^{\prime}$ is the observed first-order rate constant of inactivation in the absence of the protective agent, and $k^{\prime}$ app the apparent inactivation constant obtained at different concentrations of $a$, the compound affording protection.

\subsection{Reduction Assay}

Ga3PDHase and $n p$-Ga3PDHase oxidized as specified above were diluted and extensively desalted/re-concentrated to remove the oxidant in $50 \mathrm{mM}$ Tris- $\mathrm{HCl} \mathrm{pH} 8.0$ using Microcon spin columns (Millipore). The oxidized enzymes were incubated with DTT or reduced TRX- $h$ in buffer $50 \mathrm{mM}$ Tris-HCl pH 8.0 (similar results were obtained in the $\mathrm{pH}$ range 7-8). After different incubation times, aliquots were withdrawn from the incubation media and assayed for enzyme activity. Previous to use, TRX- $h$ was reduced by incubation in buffer $100 \mathrm{mM}$ Tris- $\mathrm{HCl} \mathrm{pH} 8.0,5 \%(v / v)$ glycerol, $0.1 \mathrm{mM}$ EDTA, and $0.5 \mathrm{mM}$ DTT during $30 \mathrm{~min}$ at $25^{\circ} \mathrm{C}$.

\subsection{In Vitro Turbidity Assay to Detect Protein Precipitation by Oxidation}

Recombinant Ga3PDHase or $n p$-Ga3PDHase $(0.6 \mathrm{mg} / \mathrm{mL})$ were treated with $\mathrm{H}_{2} \mathrm{O}_{2}$ in buffer $50 \mathrm{mM}$ Tris- $\mathrm{HCl} \mathrm{pH} 8.0,150 \mathrm{mM} \mathrm{NaCl}, 1 \mathrm{mM}$ EDTA and $5 \%(v / v)$ glycerol at $37{ }^{\circ} \mathrm{C}$ and aliquots were withdrawn at different times ranging from 0 to $24 \mathrm{~h}$. Turbidity of samples (derived from aggregated oxidized proteins) was measured following the absorbance at $405 \mathrm{~nm}$ in a microplate reader [23]. Immediately after turbidity measurement, the samples were centrifuged (14,000 rpm, $20 \mathrm{~min})$ to separate soluble and insoluble fractions. All samples were subjected to SDS-PAGE [40].

\subsection{Colorimetric Reduced Thiol Determination}

Determination of reduced thiol residues in both recombinant Ga3PDHases under reduced and oxidized state was assayed as previously described by Ellman [43]. Ga3PDHase (12 $\mu \mathrm{M})$ was oxidized with $1 \mathrm{mM} \mathrm{H}_{2} \mathrm{O}_{2}$ for 5 min and $n p$-Ga3PDHase $(18 \mu \mathrm{M})$ was oxidized with $3 \mathrm{mM} \mathrm{H}_{2} \mathrm{O}_{2}$ for 20 min in buffer $100 \mathrm{mM}$ Tris- $\mathrm{HCl} \mathrm{pH} 8.0,150 \mathrm{mM} \mathrm{NaCl}$ at $25^{\circ} \mathrm{C}$. In both cases the reduced state was achieved by incubation with $1 \mathrm{mM}$ DTT for $20 \mathrm{~min}$. After treatments, proteins were desalted by centrifugation 
using Microcon spin columns (Millipore). For determination of reduced thiol residues in the native proteins an aliquot was incubated $30 \mathrm{~min}$ with $2 \mathrm{mM}$ DTNB (5,5'-ditiobis(2-benzoate)) in buffer $100 \mathrm{mM}$ Tris- $\mathrm{HCl} \mathrm{pH} 8.0,150 \mathrm{mM} \mathrm{NaCl}$ at $25^{\circ} \mathrm{C}$. Color development was measured at $405 \mathrm{~nm}$ in a microplate reader.

\section{Conclusions}

In this work, we performed a comparative analysis of posttranslational redox regulation between enzymes acting in parallel on the glycolytic pathway. The results obtained at the proteins molecular level, led us to conclude that Ga3P partitioning between Ga3PDHase and $n p$-Ga3PDHase would change under different metabolic scenarios, with a different balance in energy or reducing power synthesis. The outcomes indicate that oxidative conditions would favor the Ga3P metabolism via $n p$-Ga3PDHase, increasing the synthesis of reducing power, which in turn would favor antioxidant systems action to cope with oxidative stress.

\section{Acknowledgments}

Financial Source: ANPCyT (PICT'08 No. 1754 and PICT'11 No. 1986), CONICET (PIP 2519), and UNL (CAI+D Redes \& Orientado). CVP, SAG and AAI are members of the investigator career from CONICET.

\section{References}

1. Givan, C.V. Evolving concepts in plant glycolysis: Two centuries of progress. Biol. Rev. 1999, 74, 277-309.

2. Plaxton, W.C. The Organization and regulation of plant glycolysis. Annu. Rev. Plant Physiol. Plant Mol. Biol. 1996, 47, 185-214.

3. Iglesias, A.A. On the metabolism of triose-phosphates in photosynthetic cells. Their involvement on the trafic of ATP and NADPH. Biochem. Educ. 1990, 18, 1-4.

4. Bustos, D.M.; Bustamante, C.A.; Iglesias, A.A. Involvement of non-phosphorylating glyceraldehyde-3-phosphate dehydrogenase in response to oxidative stress. J. Plant Physiol. 2008, 165, 456-461.

5. Bustos, D.M.; Iglesias, A.A. Non-phosphorylating glyceraldehyde-3-phosphate dehydrogenase is post-translationally phosphorylated in heterotrophic cells of wheat (Triticum aestivum). FEBS Lett. 2002, 530, 169-173.

6. Bustos, D.M.; Iglesias, A.A. Phosphorylated non-phosphorylating glyceraldehyde-3-phosphate dehydrogenase from heterotrophic cells of wheat interacts with 14-3-3 proteins. Plant Physiol. 2003, 133, 2081-2088.

7. Piattoni, C.V.; Bustos, D.M.; Guerrero, S.A.; Iglesias, A.A. Non-phosphorylating glyceraldehyde-3-phosphate dehydrogenase is phosphorylated in wheat endosperm at Ser404 by a SNF1-related protein kinase allosterically inhibited by ribose 5 phosphate. Plant Physiol. 2011, $156,1337-1350$. 
8. Rius, S.P.; Casati, P.; Iglesias, A.A.; Gomez-Casati, D.F. Characterization of an Arabidopsis thaliana mutant lacking a cytosolic non-phosphorylating glyceraldehyde-3-phosphate dehydrogenase. Plant Mol. Biol. 2006, 61, 945-957.

9. Baena-Gonzalez, E.; Rolland, F.; Thevelein, J.M.; Sheen, J. A central integrator of transcription networks in plant stress and energy signalling. Nature 2007, 448, 938-942.

10. Bedhomme, M.; Adamo, M.; Marchand, C.H.; Couturier, J.; Rouhier, N.; Lemaire, S.D.; Zaffagnini, M.; Trost, P. Glutathionylation of cytosolic glyceraldehyde-3-phosphate dehydrogenase from the model plant Arabidopsis thaliana is reversed by both glutaredoxins and thioredoxins in vitro. Biochem. J. 2012, 445, 337-347.

11. Hancock, J.T.; Henson, D.; Nyirenda, M.; Desikan, R.; Harrison, J.; Lewis, M.; Hughes, J.; Neill, S.J. Proteomic identification of glyceraldehyde 3-phosphate dehydrogenase as an inhibitory target of hydrogen peroxide in Arabidopsis. Plant Physiol. Biochem. 2005, 43, 828-835.

12. Holtgrefe, S.; Gohlke, J.; Starmann, J.; Druce, S.; Klocke, S.; Altmann, B.; Wojtera, J.; Lindermayr, C.; Scheibe, R. Regulation of plant cytosolic glyceraldehyde 3-phosphate dehydrogenase isoforms by thiol modifications. Physiol. Plant 2008, 133, 211-228.

13. Rius, S.P.; Casati, P.; Iglesias, A.A.; Gomez-Casati, D.F. Characterization of Arabidopsis lines deficient in GAPC-1, a cytosolic NAD-dependent glyceraldehyde-3-phosphate dehydrogenase. Plant Physiol. 2008, 148, 1655-1667.

14. Piattoni, C.V.; Rius, S.P.; Gomez-Casati, D.F.; Guerrero, S.A.; Iglesias, A.A. Heterologous expression of non-phosphorylating glyceraldehyde-3-phosphate dehydrogenase from Triticum aestivum and Arabidopsis thaliana. Biochimie 2010, 92, 909-913.

15. Schulman, M.D.; Gibbs, M. D-glyceraldehyde 3-phosphate dehydrogenases of higher plants. Plant Physiol. 1968, 43, 1805-1812.

16. Kitz, R.; Wilson, I.B. Esters of methanesulfonic acid as irreversible inhibitors of acetylcholinesterase. J. Biol. Chem. 1962, 237, 3245-3249.

17. Nagradova, N.K. Study of the properties of phosphorylating D-glyceraldehyde-3-phosphate dehydrogenase. Biochemistry 2001, 66, 1067-1076.

18. Marchal, S.; Branlant, G. Characterization of the amino acids involved in substrate specificity of nonphosphorylating glyceraldehyde-3-phosphate dehydrogenase from Streptococcus mutans. J. Biol. Chem. 2002, 277, 39235-39242.

19. Marchal, S.; Cobessi, D.; Rahuel-Clermont, S.; Tete-Favier, F.; Aubry, A.; Branlant, G. Chemical mechanism and substrate binding sites of NADP-dependent aldehyde dehydrogenase from Streptococcus mutans. Chem. Biol. Interact. 2001, 130-132, 15-28.

20. Quan, L.J.; Zhang, B.; Shi, W.W.; Li, H.Y. Hydrogen peroxide in plants: A versatile molecule of the reactive oxygen species network. J. Integr. Plant Biol. 2008, 50, 2-18.

21. Arias, D.G.; Piattoni, C.V.; Guerrero, S.A.; Iglesias, A.A. Biochemical Mechanisms for the Maintenance of Oxidative Stress under Control in Plants. In Handbook of Plant and Crop Stress, Third Edition; Pessarakli, M., Ed.; Taylor and Francis Group, LLC: Boca Raton, FL, USA, 2011; pp. 157-190.

22. Bustos, D.M.; Iglesias, A.A. A model for the interaction between plant GAPN and 14-3-3zeta using protein-protein docking calculations, electrostatic potentials and kinetics. J. Mol. Graph. Model 2005, 23, 490-502. 
23. Nakajima, H.; Amano, W.; Fujita, A.; Fukuhara, A.; Azuma, Y.T.; Hata, F.; Inui, T.; Takeuchi, T. The active site cysteine of the proapoptotic protein glyceraldehyde-3-phosphate dehydrogenase is essential in oxidative stress-induced aggregation and cell death. J. Biol. Chem. 2007, 282, $26562-26574$.

24. Gelhaye, E.; Rouhier, N.; Navrot, N.; Jacquot, J.P. The plant thioredoxin system. Cell Mol. Life Sci. 2005, 62, 24-35.

25. Gelhaye, E.; Rouhier, N.; Jacquot, J.P. The thioredoxin h system of higher plants. Plant Physiol. Biochem. 2004, 42, 265-271.

26. Hara, M.R.; Agrawal, N.; Kim, S.F.; Cascio, M.B.; Fujimuro, M.; Ozeki, Y.; Takahashi, M.; Cheah, J.H.; Tankou, S.K.; Hester, L.D.; et al. S-nitrosylated GAPDH initiates apoptotic cell death by nuclear translocation following Siah1 binding. Nat. Cell Biol. 2005, 7, 665-674.

27. Hara, M.R.; Snyder, S.H. Nitric oxide-GAPDH-Siah: A novel cell death cascade. Cell Mol. Neurobiol. 2006, 26, 527-538.

28. Dietz, K.J.; Jacob, S.; Oelze, M.L.; Laxa, M.; Tognetti, V.; de Miranda, S.M.; Baier, M.; Finkemeier, I. The function of peroxiredoxins in plant organelle redox metabolism. J. Exp. Bot. 2006, 57, 1697-1709.

29. Smirnoff, N. Antioxidants and Reactive Oxygen Species in Plants; Blackwell Publishing Ltd.: Oxford, UK, 2005.

30. Sirover, M.A. On the functional diversity of glyceraldehyde-3-phosphate dehydrogenase: Biochemical mechanisms and regulatory control. Biochim. Biophys. Acta 2011, 1810, 741-751.

31. Azam, S.; Jouvet, N.; Jilani, A.; Vongsamphanh, R.; Yang, X.; Yang, S.; Ramotar, D. Human glyceraldehyde-3-phosphate dehydrogenase plays a direct role in reactivating oxidized forms of the DNA repair enzyme APE1. J. Biol. Chem. 2008, 283, 30632-30641.

32. Nakajima, H.; Amano, W.; Kubo, T.; Fukuhara, A.; Ihara, H.; Azuma, Y.T.; Tajima, H.; Inui, T.; Sawa, A.; Takeuchi, T. Glyceraldehyde-3-phosphate dehydrogenase aggregate formation participates in oxidative stress-induced cell death. J. Biol. Chem. 2009, 284, 34331-34341.

33. Sen, N.; Hara, M.R.; Kornberg, M.D.; Cascio, M.B.; Bae, B.I.; Shahani, N.; Thomas, B.; Dawson, T.M.; Dawson, V.L.; Snyder, S.H.; Sawa, A. Nitric oxide-induced nuclear GAPDH activates p300/CBP and mediates apoptosis. Nat. Cell Biol. 2008, 10, 866-873.

34. Neill, S.; Desikan, R.; Hancock, J. Hydrogen peroxide signalling. Curr. Opin. Plant Biol. 2002, 5, 388-395.

35. Gechev, T.S.; van Breusegem, F.; Stone, J.M.; Denev, I.; Laloi, C. Reactive oxygen species as signals that modulate plant stress responses and programmed cell death. Bioessays 2006, 28, 1091-1101.

36. Hancock, J.; Desikan, R.; Harrison, J.; Bright, J.; Hooley, R.; Neill, S. Doing the unexpected: Proteins involved in hydrogen peroxide perception. J. Exp. Bot. 2006, 57, 1711-1718.

37. Guo, L.; Devaiah, S.P.; Narasimhan, R.; Pan, X.; Zhang, Y.; Zhang, W.; Wang, X. Cytosolic glyceraldehyde-3-phosphate dehydrogenases interact with phospholipase ddelta to transduce hydrogen peroxide signals in the Arabidopsis response to stress. Plant Cell 2012, 24, 2200-2212.

38. Taniguchi, M.; Miyake, H. Redox-shuttling between chloroplast and cytosol: Integration of intra-chloroplast and extra-chloroplast metabolism. Curr. Opin. Plant Biol. 2012, 15, 252-260. 
39. Bradford, M.M. A rapid and sensitive method for the quantitation of microgram quantities of protein utilizing the principle of protein-dye binding. Anal. Biochem. 1976, 72, 248-254.

40. Laemmli, U.K. Cleavage of structural proteins during the assembly of the head of bacteriophage T4. Nature 1970, 227, 680-685.

41. Gómez Casati, D.F.; Sesma, J.I.; Iglesias, A.A. Structural and kinetic characterization of NADP-dependent, non-phosphorylating glyceraldehyde-3-phosphate dehydrogenase from celery leaves. Plant Sci. 2000, 154, 107-115.

42. Mildvan, A.S.; Leigh, R.A. Determination of co-factor dissociation constants from the kinetics of inhibition of enzymes. Biochim. Biophys. Acta 1964, 89, 393-397.

43. Ellman, G.L. A colorimetric method for determining low concentrations of mercaptans. Arch. Biochem. Biophys. 1958, 74, 443-450.

(C) 2013 by the authors; licensee MDPI, Basel, Switzerland. This article is an open access article distributed under the terms and conditions of the Creative Commons Attribution license (http://creativecommons.org/licenses/by/3.0/). 